\title{
Study on the Modification Experiment of Talc as Filter Aid
}

\author{
Yang Shuangchun ${ }^{1, a}$, Li Wei $^{1, b}$, Li Sifan ${ }^{1, c}$, Pan Yi ${ }^{1, d}$, Guo Mingzhe ${ }^{1, e}$, Liu \\ Zijie $^{2, f,}$, Zhang Haiyan ${ }^{2, f}$
}

\begin{abstract}
1, Liaoning Shihua Universtiy Liaoning Fushun 113001 China
2, College of Petroleum and Chemical Engineering, Qinzhou University, Qinzhou 535011, China

aEmail: panhongxiang@126.com; bEmail: 1075096083@qq.com; cEmail: 474570272@qq.com dEmail: panyi_bj@126.com; eEmail: 1209175715@qq.com; fEmail: shiyougongchengxi@126.com
\end{abstract}

\section{Keywords: Talcum powder, Microwave-acid Modified, DTAB, Filter Aid}

Abstract: Considering the disadvantages of general filter aid, a new type of talc filter aid was researched and developed by the two-step approach. The first step was that the talcum powder were heated by microwave in the acid solution. The second step was that the talcum powder was put into dodecyltrimethylammonium bromide solution for optimum time at the optimum temperature. The results showed that the optimum conditions were: the amount of $0.05 \mathrm{mmol} / \mathrm{L}$ DTAB was $200 \mathrm{~mL}$, the modified temperature was $80^{\circ} \mathrm{C}$ and the modified time was $60 \mathrm{~min}$. When the filtrate accumulated to $25 \mathrm{~mL}$, the filtration time with talc filter aid was 17.70 s which was more than that with the diatomite filter aid (the filtration time without any filter aid was $76.69 \mathrm{~s}$ ). The membrane flux of microfiltration was the largest $\left(0.010 \mathrm{~L} / \mathrm{m}^{2} \bullet \mathrm{s}\right)$ when talc filter aid was added into the Kaolin suspension.

\section{Introduction}

For almost decades of years, general filter aid has been widely researched in water filtration. The disadvantages of filter aid such as diatomite, perlite and cellulose, are obvious. But talc, $\mathrm{Mg}_{3}\left(\mathrm{Si}_{4} \mathrm{O}_{10}\right)(\mathrm{OH})_{2}$, is a major hydrous magnesium silicate with the chemical composition of $\mathrm{MgO}$ $31.72 \%, \mathrm{SiO}_{2} 63.52 \%, \mathrm{H}_{2} \mathrm{O} 4.76 \%$. The crystal structure of talc is a monoclinic system which consists of layers of brucite octahedral, sandwiched between silica tetrahedron sheets ${ }^{[1]}$. Such successive layers of talc are bonded together by van der Waals force. A continuous network of silica tetrahedron sheets are connected by bridging oxygen atoms, which are all toward the side. The energy of face surface has relatively large difference to the edge surface. The face surface has a high hydrophobicity because it lacks active sites of electron donor and electron acceptor, which offer some positions to make oxygen and silicon atoms react with water molecules. In addition, talc has some intrinsic properties such as chemical inertness, high thermal stability, better lubricity, low electrical conductivity, unique pore structure, low costs and rich resource ${ }^{[2]}$. So the talc was considered as filter aid because its physicochemical properties and structure are similar to general filter aid. Also, the lubricity and hydrophobicity of talc are improve, as well as its particle size. At the same time, it is found that the adsorptive ability of modified talcum powder by nitric acid is higher than original talcum powder, and acid could dissolve the inorganic salts, which open the internal pore in talcum powder ${ }^{[3]}$. And modification by microwave-heating is more rapid and more uniform, which could greatly reduce heating time and energy consumption, and the heating quality also could be improved ${ }^{[4]}$. Also, some researchers modified talc coated with cationic surface active agent so the adsorption of talc to pollutants with negative charges was improved. 
Therefore, it is necessary to develop the special filter aid- talc filter aid which is much more efficient and cheap. Taken together, the work presented in this paper represents an attempt to modify talc with two-step approach. First, talcum powder was modified by microwave and organic acid were used to improve the activity of most groups and remove the impurities and water. Second, the treated talcum powder were modified with dodecyltrimethylammonium bromide (DTAB). The optimum conditions such as the amount of DTAB, modified time and modified temperature between DTAB and microwave-assisted acidification talcum powder (M-A-T) were determined.DTAB which formed by hydrophobic hydrocarbon chain and hydrophilic polar group is a kind of cationic surfactant active agent with strong hydrophobicity. Its Hydrophile LipophileBalance value is 7 9. As a consequence, DTAB modifier has an influence on hydrophobicity, lubricity and particle size of talc. Last, the modified talcum powder with the two-step approach (D-M-A-T) was used to the filtration experiments of Kaolin suspension. The performances of filter aid were valued by filtration rate and water content of filter cake.

\section{Experiments}

\section{Materials}

The Talcum powder (1250 mesh) samples (Haicheng City, China), acetic acid Dodecyltrimethylammonium Bromide (DTAB) $\mathrm{Kaolin}\left(\mathrm{Al}_{2} \mathrm{O}_{3} \cdot 2 \mathrm{SiO}_{2} \cdot 2 \mathrm{H}_{2} \mathrm{O}\right)$, diatomite, Silver nitrate $\left(\mathrm{AgNO}_{3}\right)$, hybrid fiber microfiltration membrane were used in this experiment.

\section{Pretreatment of talcum powder}

The talcum powder were mixed with $300 \mathrm{~mL}$ distilled water in a $500 \mathrm{~mL}$ beaker, then the mixtures were stirred continuously for $1 \mathrm{~h}$. After stirring, all mixtures were still for $1 \mathrm{~h}$ to remove the small suspended impurity. This process was repeated many times until there were not suspension matters which can be seen . At last, the cleaned talcum powder were dried at $105^{\circ} \mathrm{C}$ in the loft drier to keep off residues water.

\section{Microwave assisted acid modification of talcum powder}

$10 \mathrm{~g}$ samples of cleaned talcum powder were put into $100 \mathrm{~mL}$ acetic acid solution for $9 \mathrm{~h}$ at $40^{\circ} \mathrm{C}$. The samples solution were treated by the microwave synthesis system for 5 minutes on $600 \mathrm{~W}$. Then samples were dried (marked M-A-T).

\section{M-A-T modification with DTAB}

$5 \mathrm{mmol} / \mathrm{L}$ DTAB solution and 5g M-A-T samples were stirred for different times $(40,60,80$, $100,120$ minutes $)$ at different temperatures $\left(50,60,70,80,90^{\circ} \mathrm{C}\right)$. Then each solution was filtered in order to obtain the required precipitate, and then the precipitate was washed with the deioned water several times to get required talc modified with DTAB. The samples were dried at $90^{\circ} \mathrm{C}$ in the loft drier until dry( marked M-A-D-T).

\section{Pretreatment of microfiltration membrane}

Hybrid fiber microfiltration membrane were soaked in the deioned water for $4 \mathrm{~h}$ at $70^{\circ} \mathrm{C}$. Then the above hybrid fiber microfiltration membrane were transferred into another beaker, soaked again for $12 \mathrm{~h}$.

\section{Batch filtering experiments}

Filtration flow experiment was that $0.05 \mathrm{~g}$ M-A-D-T were added into $40 \mathrm{ml}$ Kaolin suspension which quality fraction was $8 \%$, then the mixtures were stirring for 3 minutes. Meanwhile, the vacuum pump was opened to constant pressure $0.09 \mathrm{MPa}$, and then the mixtures were transferred into Buchner funnel, at the same time, we began to count filtration time when the filtrate were accumulated to $5 \mathrm{~mL}$. After the process of filtration, the filter cake were placed in the dry 
watch-glass, weighed, and dried to constant weight. Then water content of filter cake and membrane flux were calculated, the membrane flux was calculated with the following formula:

$$
\mathrm{J}=\mathrm{V} /(\mathrm{T} \cdot \mathrm{S})
$$

Where: $\mathrm{J}$ is membrane flux $\left(\mathrm{L} / \mathrm{m}^{2} \bullet \mathrm{s}\right), \mathrm{V}$ is volume of filtrate out of funnel $(\mathrm{L})$; T is filtration time (s); $\mathrm{S}$ is active area of membrane $\left(\mathrm{m}^{2}\right)$.

\section{Results and discussion}

\section{Effect of modified temperature on filtration of talc filter aid}

Fig. 1 showed that the filtration rate of Kaolin suspension increased when the modified temperature increased and the highest filtration rate reached $80^{\circ} \mathrm{C}$. When the volume of filtrate solution of M-A-D-T were accumulated to $25 \mathrm{ml}$, the time was 204.50 s (filtrate time without adding the filter aid is less 59.50 s than the filtrate time of M-A-D-T). The above results probably because when the modified temperature is low that the extent of reaction also will be little. However, as temperature rise, on one hand, abundant energy is provided, so chemical adsorption between M-A-T and cationic surface active agent will happen;on the other hand, because reactant molecules move faster, the contact area and probability of reacting will increase, the chemical adsorption consequently is more sufficient. Therefore, the purity and hydrophobicity of talc filter aid will increase, and then the performances of filtration will be better. So the optimal modified temperature was choose at $80^{\circ} \mathrm{C}$.

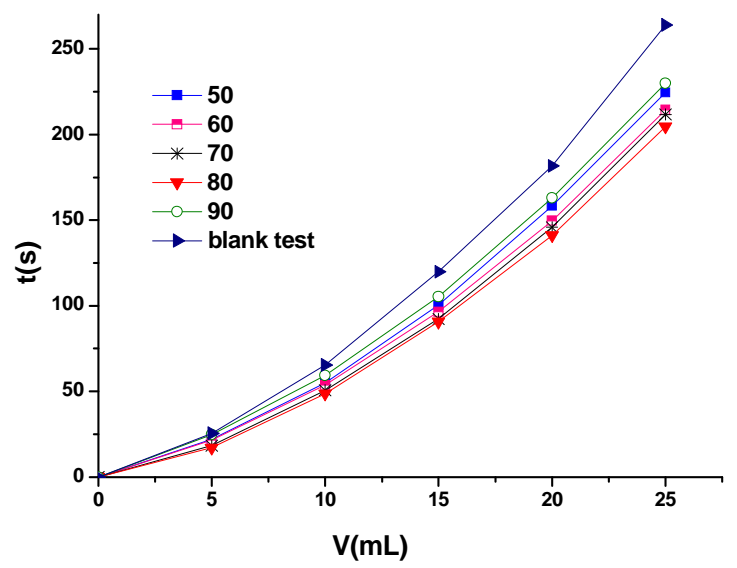

Fig. 1. Effect of modified temperature on filtration rate of talc filter aid

\section{Effect of modified time on filtration of talc filter aid}

From Fig. 2, it was observed that the filtration rate of Kaolin suspension increased with modified time prolonged and reached the highest at $60 \mathrm{~min}$. Subsequently, the filtration rate decrease gradually, which was faster than the filtration rate when samples did not add the filter aid. It might be interpreted that DTAB and M-A-T did not react sufficiently in the short time, and with the reaction time increasing the adsorption on $\mathrm{M}-\mathrm{A}-\mathrm{T}$ of cationic surface active agent will get to equilibrium, and then the adsorbing capacity were no longer changed because of the disappearance of the active site. Moreover, in the experimental process the reactants formed emulsion solution if the Kaolin suspension were stirred for the long time. So 60 mins was the demanded modified time. 


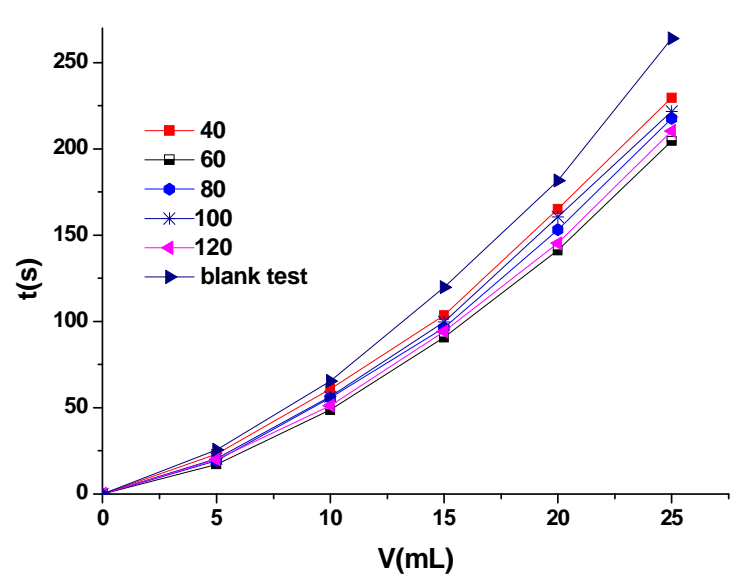

Fig. 2. Effect of modified time on filtration rate of talc filter aid

\section{Effect of the amount of DTAB on filtration of talc filter aid}

The results were given in Fig. 3. It was noted that when the amount of DTAB was $200 \mathrm{~mL}$, the filtration rate of Kaolin suspension was found to reach the highest. But a decreased phenomenon occurred when we continued to add DTAB. And the filtration rate was lowest when the amount of DTAB was $500 \mathrm{~mL}$. The reason might be the adsorbing capacity of M-A-T on adsorption of cationic surface active agent was already saturated when the amount of DTAB was $200 \mathrm{~mL}$, and the evenness of adsorption was influenced when the amount of DTAB was too much, and then there were part of the water molecules went into the spaces in the process of adsorption, also, a lot of froth was formed under the condition of stirring. The optimum amount of DTAB was $200 \mathrm{~mL}$.

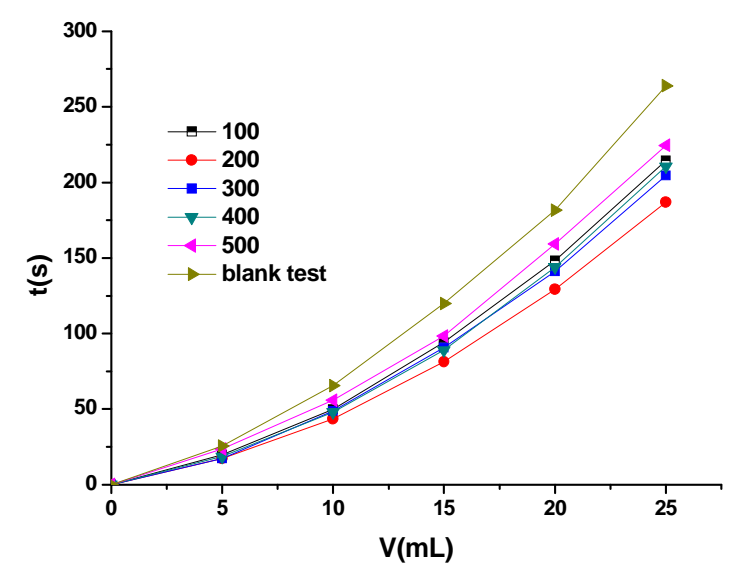

Fig. 3. Effect of the amount of DTAB on filtration rate of talc filter aid

\section{Comparison of talc filter aid with diatomite filter aid}

The same amount of talc filter aid under the optimum conditions and diatomite filter aid were added into the kaolin suspension, respectively. The results were showed in Fig. 4. By comparison, the filtration rate with talc filter aid was as fast as the filtration rate which added diatomite filter aid when the filtrate accumulated to $5 \mathrm{~mL}$. However, compared with diatomite filter aid, the filtration time with talc filter aid gradually shorten as the cumulative filtrate increased, and when the filtrate was accumulated to $25 \mathrm{~mL}$, the filtration time with talc filter aid was 17.70 s more than the filtration time with the diatomite filter aid and 76.69s more than the filtration time without any filter aid. 


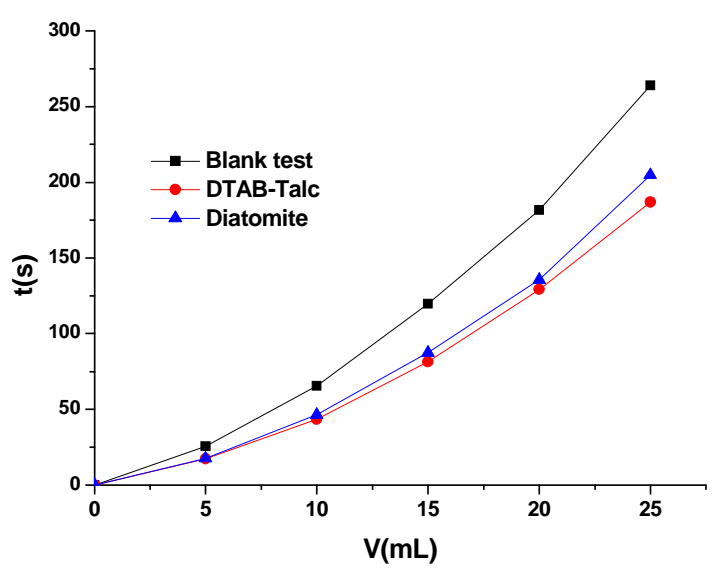

Fig. 4. Effect on filtration rate of talc filter aid and diatomite filter aid

\section{Conclusions}

The influences of the new talc filter aid which was made by the two-step approach were studied in this paper. (1)The optimum conditions that DTAB reacted with M-A-T were that: M-A-T were stirred with $0.05 \mathrm{mmol} / \mathrm{L} \mathrm{DTAB}$ at $80^{\circ} \mathrm{C}$ for $60 \mathrm{~min}$, and the amount of DTAB was $200 \mathrm{ml}$. (2)The membrane flux of microfiltration was the largest $\left(0.010 \mathrm{~L} / \mathrm{m}^{2} \bullet \mathrm{s}\right)$ when we added talc filter aid into the kaolin suspension.We found that the performances of talc filter aid were better comparig with diatomite filter aid. When the filtrate was accumulated to $25 \mathrm{~mL}$, the filtration time with talc filter aid was 17.70 s more than the filtration time with the diatomite filter aid and $76.69 \mathrm{~s}$ more than the filtration time without any filter aid.

\section{Acknowledgement}

The authors are thankful to LJQ (2015063), China, Liaoning Provincial Education Department for financial support of "Program for Liaoning Outstanding Young Scholar in University". The authors are also thankful to "the Open Project Program of the Qinzhou Key Laboratory of Oil and Natural Gas Resource Refined Utilization and Safety Control (2016KLOG03) ”support.

\section{References}

[1] Mierczynska-Vasilev A. and Beattie D.A: Int.J.Miner.Process Vol. 118 (2013), p. 34-36

[2] Chen R. and Jia X.Z: Non-Metall. Min.Ind.Her (2012), p.1-12

[3] Liu W.L., Zhao S.L., Cui S., Yang S.C. and Shang L.Y.: Adv.Mater., Res. (2013), p. 610-613

[4] Crane C.A., Pantoya M.L., Weeks B.L., and Saed M.: Powder Technol. (2014), p. 113-125 